\title{
Prevalence of Sleep Disturbances During COVID-19 Pandemic in a Nepalese Population: A Cross-Sectional Study
}

\author{
Avinash Chandra ${ }^{1,2}$, Pooja Prakash ${ }^{3}$, Nabina Sharma ${ }^{4}$, Ayush Chandra ${ }^{5,6}$ \\ ${ }^{1}$ Annapurna Neurological Institute and Allied Sciences, Maitighar, Kathmandu, \\ ${ }^{2}$ Department of Neurology, National Academy of Medical Sciences, Bir Hospital, Kathmandu, \\ ${ }^{3}$ Gandaki Medical College and Teaching Hospital, Pokhara, Nepal \\ ${ }^{4}$ Laurentian University, Sudbury, Canada \\ ${ }^{5}$ Multiple Sclerosis Society Nepal, Kathmandu, Nepal \\ ${ }^{6}$ Department of Clinical Medicine, Tianjin Medical University, Tianjin, China
}

Received April 21, 2021

Revised June 24, 2021

Accepted August 9, 2021

Address for correspondence

Ayush Chandra, MBBS

Department of

Clinical Medicine,

Tianjin Medical University,

Tianjin 300070, China

Tel: +977 9840149436

E-mail: ayushchandra1995

@yahoo.com
Objectives: The coronavirus disease (COVID-19) pandemic and news of daily increasing cases inside Nepal and worldwide is adding to the fear that leads to anger, anxiety, frustration, and stress, emotions that directly affect sleep quality. This study aimed to assess sleep disturbances during the COVID-19 pandemic in a Nepalese population. Methods: This cross-sectional study recruited 206 Nepali residents who completed anonymous self-administered questionnaires. The Insomnia Severity Index (ISI) questionnaire was used to measure sleep disturbances before and after the COVID-19 pandemic. The gathered data were analyzed using descriptive statistics and inferential statistics using SPSS version 20 statistical software. Results: There was a significant variation in sleep disturbances among Nepalese residents before versus after the COVID-19 pandemic $(p<0.001)$. The prevalence of clinical moderate insomnia has increased tremendously in Nepalese individuals. Before the pandemic's onset, only $3.9 \%$ of the participants had moderate to severe levels of clinical insomnia; after its onset, this value increased to $17.5 \%$. The mean ISI scores were $6.35 \pm 4.65$ and $8.01 \pm 6.01$ before and after the pandemic's onset, respectively. Conclusions: Our study findings suggest that people are suffering tremendously with sleep disturbances and calls for further research and active measures to help increase sleep quality during the COVID-19 pandemic.

J Sleep Med 2021;18(3):145-153

Keywords: COVID-19; Insomnia; Mental health; Sleep disturbances.

\section{INTRODUCTION}

Sleep (or at least a physiological period of quiescence) is a highly conserved behavior that occurs in animals ranging from fruit flies to humans. ${ }^{1}$ As a result, a substantial proportion of the human lifespan is spent in this mysterious state. Sleep is vital to human health and critical for neurobehavioral, cognitive, memory consolidation, ${ }^{2}$ nociception, ${ }^{3}$ appetite regulation, and immune and hormonal functions. ${ }^{4}$ The American Academy of Sleep Medicine and Sleep Research Society stated that sleeping less than 7 hours or more than 9 hours per night is associated with health risks. ${ }^{5}$ Sleep disruptions can indicate or even cause more serious underlying medical conditions.

This is an Open Access article distributed under the terms of the Creative Commons Attribution Non-Commercial License (https://creativecommons.org/licenses/by-nc/4.0) which permits unrestricted non-commercial use, distribution, and reproduction in any medium, provided the original work is properly cited.
Sleep quality and disturbances have strong correlations with indices such as occupational activities, physical and psychological well-being, and even death. ${ }^{6}$ The increase in sleep difficulties is more common among people with a higher level of depression, anxiety, and stress symptomatology associated with a feeling of time dilatation. ${ }^{7}$ A systematic review and meta-analysis reported that, during the pandemic, about one-third of participants suffered from psychological symptoms, including a $43 \%$ prevalence of stress, $37 \%$ prevalence of anxiety, $43 \%$ prevalence of depression, and $43 \%$ prevalence of sleep disturbances. ${ }^{8}$ A survey of an Indian population revealed a $9 \%$ prevalence of insomnia and $30 \%$ prevalence of occasional insomnia. ${ }^{9}$ Insomnia is characterized by difficulty falling asleep, difficulty staying asleep, waking too early, or feeling unrefreshed upon waking. There are clear reciprocal dependencies between sleep duration, quality, and immune responses against viral, bacte- 
rial, and parasitic pathogens, the latter of which alter sleep patterns. An improved sleep quality and duration in a population may mitigate the propagation and severity of severe acute respiratory syndrome coronavirus 2 (SARS-CoV-2) infection. ${ }^{10}$

Infectious disease epidemics affect the physical health of patients as well as the psychological health and well-being of the non-infected population. Previous studies demonstrated that the prevalence of novel infectious diseases, such as SARS, can increase anxiety, depression, and stress levels in the general population, all of which directly affect sleep. ${ }^{11}$ A systemic review stated that most patients (54\%) with SARS or Middle East respiratory syndrome during the previous pandemic exhibited insomnia. ${ }^{12}$ A post-SARS patient in Ontario, Canada, had symptoms of pre- and post-sleep fatigue, sleep instability, and difficulty sleeping. ${ }^{13}$ Survivors of an Ebola epidemic in Africa reported feeling anxiety (14\%), depression (15\%), and insomnia (22\%). ${ }^{14}$ The sleep problems arising during the coronavirus disease (COVID-19) outbreak are severe and affect approximately $40 \%$ of people. ${ }^{15}$ SARS-CoV-2 was first identified in December 2019 in Wuhan city, central China. ${ }^{16}$ As of May 12, 2020, the World Health Organization (WHO) reported a total of 4,006,257 confirmed cases globally with a mortality rate of 278,892 and 88,891 new cases and 4,531 deaths in the previous 24 hours; unfortunately, the numbers are only increasing. ${ }^{17}$ The Nepalese Ministry of Health reported more than 400 confirmed COVIDpositive cases as of May 20,2020, a number that is expected to rise sharply. ${ }^{18}$ The government of Nepal announced a nationwide total lockdown on March 24, 2020 in a bid to stop COVID-19 from spreading out of control. The lockdown halted the movement of people and prompted the shutdown of industry, schools, and the majority of institutions.

During the pandemic and lockdown period, reduced physical activity and disrupted routines became the main threats to sleep patterns. ${ }^{19}$ Thinking about the COVID-19 crisis and watching news about it cause stress among people, becoming a primary cause of insomnia. Reducing TV time, increasing physical activity levels, following the pre-lockdown work routine, and keeping a positive attitude will improve an individual's sleep quality. ${ }^{20}$ An estimated $33.24 \%$ of people from Bangladesh reported sleep disturbances during the COVID-19 lockdown, and the associated risk factors were family members being infected with COVID-19, working from home, regular use of the Internet for more than 5 hours, unemployment, being at high risk of COVID-19 infection, and following a disturbed sleeping schedule. ${ }^{21}$ In India, 62\% of patients with COVID-19 complained of sleep disturbances. ${ }^{22}$ A study from Nepal reported that 33.9\% of health workers had symptoms of insomnia during the COVID-19 pandemic. $^{23}$

Many studies have assessed the impact of COVID-19 on sleep disorders. ${ }^{24}$ Psychological and sleep problems have increased during interpersonal isolation due to COVID-19 among Chinese people, including $16 \%$ suffering from insomnia. ${ }^{25} \mathrm{~A}$ survey on COVID impact, lockdown that disrupted sleep patterns among 1,500 respondents in India reported that $67 \%$ of those who worked from home had an altered sleep schedule, 50\% believed that their sleep pattern had been disrupted, and 81\% felt their sleep schedule would get better after the lockdown. ${ }^{20}$ In Italy during the COVID-19 lockdown, sleep timing markedly changed, with people going to bed and waking up later, spending more time in bed, and paradoxically reporting a lower sleep quality.?

Sleep disturbances, including insomnia, can be precipitated by stressful events. ${ }^{26}$ In rural areas of Peru, $29 \%$ of middle-aged and older adults had poor sleep patterns before the COVID-19 pandemic, which increased to $49 \%$ at the pandemic's peak. ${ }^{27}$ In China, symptoms of insomnia were reported in $36 \%$ of people in addition to higher levels of other health issues; for instance, $87.1 \%$ of patients with insomnia symptoms reported also having depression. ${ }^{28}$

Based on previous research evidence, we have reason to speculate that the psychological condition and sleep disturbances of the public may also be affected during the COVID-19 outbreak in Nepal. Therefore, this web-based cross-sectional study aimed to assess sleep disturbances during the COVID-19 pandemic in a Nepalese population. We hope that our study findings will provide data support for targeted interventions on psychological and mental health in the Nepalese public during the outbreak.

\section{METHODS}

\section{Study design and subjects}

This observational, cross-sectional study aimed to assess sleep disturbances during the COVID-19 pandemic in a Nepalese population. On March 11, 2020, the WHO characterized COVID-19 as a pandemic; soon thereafter (on March 24, 2020), the Nepalese government announced a nationwide total lockdown. The survey was performed from April 20 to May 2, 2020, in Nepal. A non-probability convenience sampling technique was used to select 206 Nepalese residents. The sample size was determined using the Cochran formula, ${ }^{29}$ in which the estimated proportion of the population (p) was 50\% with a $95 \%$ confidence level and a precision of at least plus or minus $10 \%$.

Nepalese residents aged 18 years or older who would read and write Nepalese or English were included in this study. Those who refused to provide study consent, had a chronic disease condition, were infected with COVID-19 or any respiratory disease, or had a history of alcohol consumption or smoking were excluded from the study. Among the 220 recruited Nepalese residents, 14 were excluded from the study (five were infected 
with COVID-19; six were unable to respond to the second set of questionnaires, that is, sleep conditions during the pandemic; and three refused to provide consent to participate). As it was not feasible to conduct a community-based national sampling survey due to lockdown in Nepal, an online survey was provided. Questionnaires were prepared in a Google form and sent via email, Facebook, and Viber messenger. The participants received a link to access the survey, which took approximately 20 minutes to complete. Subjects completed an anonymous web-based online survey after reading the written consent form and explicitly agreed to participate in the survey. This study underwent proper approval process from Internal Review Board of Annapurna Neurological Institute and Allied Sciences.

\section{Measures}

\section{Study questionnaire}

The self-structured questionnaire was developed based on a literature review and the Insomnia Severity Index (ISI). The questionnaire was adopted to gather socio-demographic variables and identify the prevalence and severity of sleep disturbances in the form of insomnia. A similar questionnaire was provided twice to the same subjects to measure the disturbances of sleep before versus during the COVID-19 pandemic. The first set of questionnaires reported on the sleep condition before the COVID-19 pandemic and lockdown started, while the second set of questionnaires captured the sleep condition after the COVID-19 pandemic was declared and the lockdown started in Nepal. The participants rated the ISI depending on their own experience regarding sleep before (March 16) and during (March 24) the lockdown.

The ISI is a brief self-reporting instrument that measures the patient's perception of his or her insomnia. The ISI targets the subjective symptoms and consequences of insomnia, as well as the degree of concerns or distress caused by those difficulties. Its content corresponds to the diagnostic criteria for insomnia. ${ }^{30}$ The ISI comprises seven items that evaluate: 1) sleep onset (initial) severity, 2) sleep maintenance (middle), 3) early morning awakening (terminal) problems, 4) satisfaction with current sleep patterns, 5) interference with daily functioning, 6) noticeable to others/impairing quality of life, and 7) level of distress caused by the sleep problem. Each item is scored on a 5-point Likert scale from 0 to 4 , yielding a total score of $0-28$. The results were interpreted as follows: absence of insomnia (0-7), subthreshold insomnia (8-14), moderate insomnia (15-21), and severe insomnia (22-28). Numerous studies have proven that the ISI is a valid and reliable instrument. ${ }^{31}$ Internal consistency was determined using Cronbach's alpha test. The Cronbach's alpha for the ISI was 0.75 .

\section{Statistical analysis}

The subjects' responses were collected using the Google form. The gathered data were analyzed using descriptive statistics and inferential statistics using SPSS version 20 statistical software (IBM Corp., Armonk, NY, USA). A descriptive analysis of frequency, percentage distribution, mean, and standard deviation were used to describe the socio-demographic variables, whereas in inferential analysis, a paired t-test was used to assess the quality of sleep before and during the COVID-19 pandemic among Nepalese residents, and the chi-square test was used to assess the association between sleep disturbance and selected variables. The Karl-Pearson correlation coefficient was used to determine the relationship between socio-demographic variables and sleep disturbances during the COVID-19 pandemic. The statistical significance level was set at $p<0.05$ (two-sided).

\section{RESULTS}

\section{Demographic characteristics and insomnia prevalence and severity}

A total of 206 Nepalese residents were recruited, of whom $96(46.6 \%)$ were female and $110(53.4 \%)$ were male. The mean age of the subjects was $29.5 \pm 9.8$ years (Table 1 ). As per the ISI, there was significant variation in sleep quality among Nepalese residents before and during the pandemic (Table 2). The prevalence of insomnia before the COVID-19 pandemic was $36.9 \%$, which increased to $47.1 \%$ during the pandemic. Similarly, before the onset of the pandemic, the prevalence of subthreshold insomnia was $33 \%$, and $3.9 \%$ of the subjects had moderate to severe insomnia that changed significantly during the pandemic period and subsequent lockdown. The prevalence of subthreshold insomnia decreased to $29.6 \%$, while the number of people with moderate insomnia increased to 34 (16.5\%) and no change was noted in the severity of clinical insomnia $(n=2$ [1\%]). The mean ISI scores before and during the COVID-19 pandemic were 6.35 \pm 4.65 and $8.01 \pm 6.01$, respectively (Table 3).

The present study revealed that subjects had severe difficulty

Table 1. Socio-demographic variables of Nepali residents who completed self-administered questionnaires

\begin{tabular}{lc}
\hline \multicolumn{1}{c}{ Variables } & Value $(\mathrm{n}=206)$ \\
\hline Sex & $96(46.6)$ \\
Female & $110(53.4)$ \\
Male & $29.5 \pm 9.8$ \\
Age $(\mathrm{yr})$ & $142(68.9)$ \\
$16-30$ yrs & $48(23.3)$ \\
$31-45$ yrs & $12(5.8)$ \\
$46-60$ yrs & $4(1.9)$ \\
$>60$ yrs &
\end{tabular}


with sleep onset (4.9\%), severe difficulty with sleep maintenance (2.9\%), very severe awakening problems (3.4\%), and very severe dissatisfaction with sleep patterns (1.5\%) even before the COVID-19 pandemic. Before the COVID-19 outbreak, 6 (2.9\%) subjects felt that their sleep quality had adversely impaired their quality of life, 9 (4.4\%) were worried about sleep problems, and $14(6.8 \%)$ experienced sleep-related interference with their daily functioning. During the pandemic period and lockdown phase, $11.7 \%$ of subjects had severe difficulty with falling asleep, $5.3 \%$ had difficulty with sleep maintenance, and $12.6 \%$ had severe awakening problems. In addition, $16 \%$ of the subjects were dissatisfied with their sleep pattern, $7.8 \%$ had an impaired quality of life, $3.9 \%$ were very worried about their sleep problems, and $11.7 \%$ reported disturbed daily living function (Table 2).

\section{Sleep quality before versus during the COVID-19 pandemic}

Table 3 presents the significant difference in sleep disturbance before versus during the COVID-19 pandemic $(t=3.23 ; p<0.001)$. The subjects experienced significantly more difficulty falling asleep $(\mathrm{t}=2.74)$ and staying asleep $(\mathrm{t}=1.98)(p<0.05$ for both) during than before the COVID-19 outbreak. The subjects' satisfaction with their current sleep patterns significantly decreased during the pandemic $(\mathrm{t}=3.03)$. There was a significant increases in sleep problem related anxiety levels $(\mathrm{t}=3.74 ; p<0.05)$ during the COVID-19 outbreak.

Table 2. Comparison of prevalence of insomnia between before and during COVID-19 pandemic among Nepali residents based on ISI $(n=206)$

\begin{tabular}{|c|c|c|c|c|c|c|c|c|c|c|}
\hline \multirow{2}{*}{$\begin{array}{l}\text { Components of } \\
\text { insomnia problem }\end{array}$} & \multicolumn{5}{|c|}{ Before COVID-19 pandemic } & \multicolumn{5}{|c|}{ During COVID-19 pandemic } \\
\hline & None & Mild & Moderate & Severe & $\begin{array}{c}\text { Very } \\
\text { severe }\end{array}$ & None & Mild & Moderate & Severe & $\begin{array}{l}\text { Very } \\
\text { severe }\end{array}$ \\
\hline Difficulty falling asleep & $107(51.9)$ & $53(25.7)$ & $36(17.5)$ & $10(4.9)$ & - & $97(47.1)$ & $44(21.4)$ & $36(17.5)$ & $24(11.7)$ & $5(2.4)$ \\
\hline Difficulty staying asleep & $107(51.9)$ & $60(29.1)$ & $31(15.0)$ & $6(2.9)$ & $2(1.0)$ & $94(45.6)$ & $61(29.6)$ & $36(17.5)$ & $11(5.3)$ & $4(1.9)$ \\
\hline Awakening problem & $86(41.7)$ & $56(27.2)$ & $42(20.4)$ & $15(7.3)$ & $7(3.4)$ & $87(42.2)$ & $41(19.9)$ & $42(20.4)$ & $26(12.6)$ & $10(4.9)$ \\
\hline $\begin{array}{l}\text { Satisfaction with current } \\
\text { sleep pattern }\end{array}$ & $43(20.9)$ & $95(46.1)$ & $56(27.2)$ & $9(4.4)$ & $3(1.5)$ & $38(18.4)$ & $78(37.9)$ & $49(23.8)$ & $33(16.0)$ & $8(3.9)$ \\
\hline Impairment of quality of life & $89(43.2)$ & $70(34.0)$ & $37(18.0)$ & $6(2.9)$ & $4(1.9)$ & $82(39.8)$ & $62(30.1)$ & $41(19.9)$ & $16(7.8)$ & $5(2.4)$ \\
\hline $\begin{array}{l}\text { Worried about current } \\
\text { sleep problem }\end{array}$ & $104(50.5)$ & $64(31.1)$ & $29(14.1)$ & $9(4.4)$ & - & $83(40.3)$ & $59(28.6)$ & $30(14.6)$ & $26(12.6)$ & $8(3.9)$ \\
\hline $\begin{array}{l}\text { Interfere with daily } \\
\text { functioning }\end{array}$ & $75(36.4)$ & $64(31.1)$ & $48(23.3)$ & $14(6.8)$ & $5(2.4)$ & $66(32.0)$ & $64(31.1)$ & $43(20.9)$ & $24(11.7)$ & $9(4.4)$ \\
\hline \multicolumn{11}{|l|}{ Result of ISI evaluation } \\
\hline Absent insomnia & \multicolumn{5}{|c|}{$130(63.1)$} & \multicolumn{5}{|c|}{$109(52.9)$} \\
\hline Subthreshold insomnia & \multicolumn{5}{|c|}{$68(33.0)$} & \multicolumn{5}{|c|}{$61(29.6)$} \\
\hline Moderate clinical insomnia & \multicolumn{5}{|c|}{$6(2.9)$} & \multicolumn{5}{|c|}{$34(16.5)$} \\
\hline Severe clinical insomnia & \multicolumn{5}{|c|}{$2(1.0)$} & \multicolumn{5}{|c|}{$2(1.0)$} \\
\hline
\end{tabular}

Data are presented as n (\%). ISI, Insomnia Severity Index; COVID-19, coronavirus disease

Table 3. Sleep disturbances before and during COVID-19 pandemic $(n=206)$

\begin{tabular}{|c|c|c|c|c|c|}
\hline \multirow{2}{*}{$\begin{array}{l}\text { Components of } \\
\text { insomnia problem }\end{array}$} & \multicolumn{2}{|c|}{ ISI score } & \multirow{2}{*}{$\begin{array}{l}95 \% \text { confidence interval } \\
\text { of the difference }\end{array}$} & \multirow{2}{*}{ "t"value } & \multirow{2}{*}{$p$} \\
\hline & Before COVID-19 & During COVID-19 & & & \\
\hline Difficulty falling asleep & $0.75 \pm 0.91$ & $1.01 \pm 1.16$ & $0.44-0.72$ & $2.74^{*}$ & 0.007 \\
\hline Difficulty staying asleep & $0.72 \pm 0.89$ & $0.88 \pm 1.01$ & $0.33-0.0001$ & $1.98^{*}$ & 0.049 \\
\hline Awakening problem & $1.03 \pm 1.12$ & $1.18 \pm 1.24$ & $0.36-0.70$ & 1.33 & 0.184 \\
\hline Satisfaction with current sleep pattern & $1.19 \pm 0.87$ & $1.49 \pm 1.20$ & $0.49-0.104$ & $3.03^{*}$ & 0.003 \\
\hline Impairment of quality of life & $0.86 \pm 0.94$ & $1.03 \pm 1.06$ & $0.34-0.01$ & 1.86 & 0.065 \\
\hline Worried about current sleep problem & $0.72 \pm 0.87$ & $1.11 \pm 1.18$ & $0.59-0.18$ & $3.74^{*}$ & $<0.001$ \\
\hline Interfere with daily functioning & $1.08 \pm 1.04$ & $1.25 \pm 1.15$ & $0.39-0.037$ & 1.63 & 0.105 \\
\hline Total score of ISI & $6.35 \pm 4.65$ & $8.01 \pm 6.01$ & $0.65-0.65$ & $3.23^{*}$ & $<0.001$ \\
\hline
\end{tabular}

Data are presented as mean \pm standard deviation. *significant at $p<0.05$. ISI, Insomnia Severity Index; COVID-19, coronavirus disease 


\section{Association between demographic characteristics and ISI scores}

The current study showed that the prevalence of insomnia was more common among females $(21.87 \%)$; similarly, less than 45 years of age had clinically severe insomnia. Table 4 shows that there was a significant association between age and sleep quality during the COVID-19 pandemic $\left(\chi^{2}=19.91\right)$ as well as interference with daily functioning such as daytime fatigue, mood, ability to function at work, and concentration ( $p<0.01$ for all). In this study, female respondents faced more problems than male respondents with waking up too early during the pandemic, that is, a $25 \%$ higher frequency, a phenomenon that was significantly associated with sleep disturbances $\left(\chi^{2}=10.31\right)$. Similarly, interference with daily functioning $\left(\chi^{2}=11.08\right)$ and distress related to current sleep problems $\left(\chi^{2}=15.27\right)$ were reported more frequently by female participants and directly associated with sleep disturbances $(p<0.05)$ (Table 5).

The study showed that sleep disturbances during the COVID-19 pandemic had a poor negative correlation with age (Ta- ble 6). However, sleep disturbances were positively correlated with female sex. Difficulty falling asleep was directly related to sleep disturbances $(p<0.05)$. Similarly, facing difficulty staying asleep, awakening problems in the early morning, distress or worry about current sleep problems, and interference with daily activities were significantly associated with the COVID-19 pandemic ( $p \leq 0.01)$. The obtained ISI scores during the COVID-19 pandemic were positively correlated with the different sexes $(p \leq$ $0.01)$. Female participants (21.87\%) reported more severe sleep disturbances than male.

\section{DISCUSSION}

The COVID-19 pandemic in 2020 is a paradigm of a new emerging zoonotic disaster ${ }^{32}$ that has caused significant medical, psychological, and social issues worldwide. This study used ISI scores to determine the sleep disturbances of Nepalese residents before versus during the COVID-19 pandemic. These findings suggest that Nepalese people were more prone to sleep

Table 4. Association of age and ISI score during COVID-19 pandemic $(n=206)$

\begin{tabular}{|c|c|c|c|c|c|c|c|}
\hline \multirow{2}{*}{$\begin{array}{l}\text { Components of } \\
\text { sleep disturbances }\end{array}$} & \multicolumn{5}{|c|}{ Insomnia severity } & \multirow{2}{*}{$\begin{array}{l}\text { Chi-square } \\
\text { test }\left(\chi^{2}\right)\end{array}$} & \multirow{2}{*}{$p$} \\
\hline & None $(0)$ & Mild (1) & Moderately (2) & Severe (3) & Very severe (4) & & \\
\hline \multicolumn{2}{|l|}{ Difficulty falling asleep } & & & & & 1.56 & 0.82 \\
\hline$<45$ & 90 & 41 & 32 & 22 & 4 & & \\
\hline$\geq 45$ & 7 & 3 & 4 & 2 & 1 & & \\
\hline \multicolumn{2}{|l|}{ Difficulty staying asleep } & & & & & 3.72 & 0.45 \\
\hline$<45$ & 83 & 58 & 33 & 11 & 4 & & \\
\hline$\geq 45$ & 11 & 3 & 3 & 0 & 0 & & \\
\hline \multicolumn{2}{|l|}{ Awakening problem } & & & & & 9.23 & 0.56 \\
\hline$<45$ & 76 & 41 & 40 & 22 & 10 & & \\
\hline$\geq 45$ & 11 & 0 & 2 & 4 & 0 & & \\
\hline \multicolumn{3}{|c|}{ Satisfaction with current sleep pattern } & & & & 0.69 & 0.95 \\
\hline$<45$ & 35 & 72 & 44 & 31 & 7 & & \\
\hline$\geq 45$ & 3 & 6 & 5 & 2 & 1 & & \\
\hline \multicolumn{3}{|c|}{ Noticeable impairment of quality of life } & & & & 5.70 & 0.22 \\
\hline$<45$ & 75 & 60 & 36 & 13 & 5 & & \\
\hline$\geq 45$ & 7 & 2 & 5 & 3 & 0 & & \\
\hline \multicolumn{3}{|c|}{ Worried about current sleep problem } & & & & 6.60 & 0.16 \\
\hline$<45$ & 78 & 56 & 25 & 22 & 8 & & \\
\hline$\geq 45$ & 5 & 3 & 5 & 4 & 0 & & \\
\hline \multicolumn{2}{|c|}{ Interfere with daily functioning } & & & & & $10.74^{*}$ & 0.03 \\
\hline$<45$ & 60 & 63 & 35 & 22 & 9 & & \\
\hline$\geq 45$ & 6 & 1 & 8 & 2 & 0 & & \\
\hline \multicolumn{2}{|l|}{ Total score of ISI } & & & & & $19.91^{*}$ & 0.008 \\
\hline$<45$ & 11 & 85 & 54 & 31 & 2 & & \\
\hline$\geq 45$ & 2 & 5 & 7 & 3 & 0 & & \\
\hline
\end{tabular}

*significant at $p<0.05$. ISI, Insomnia Severity Index; COVID-19, coronavirus disease 
Table 5. Association of sex and ISI score during COVID-19 pandemic $(n=206)$

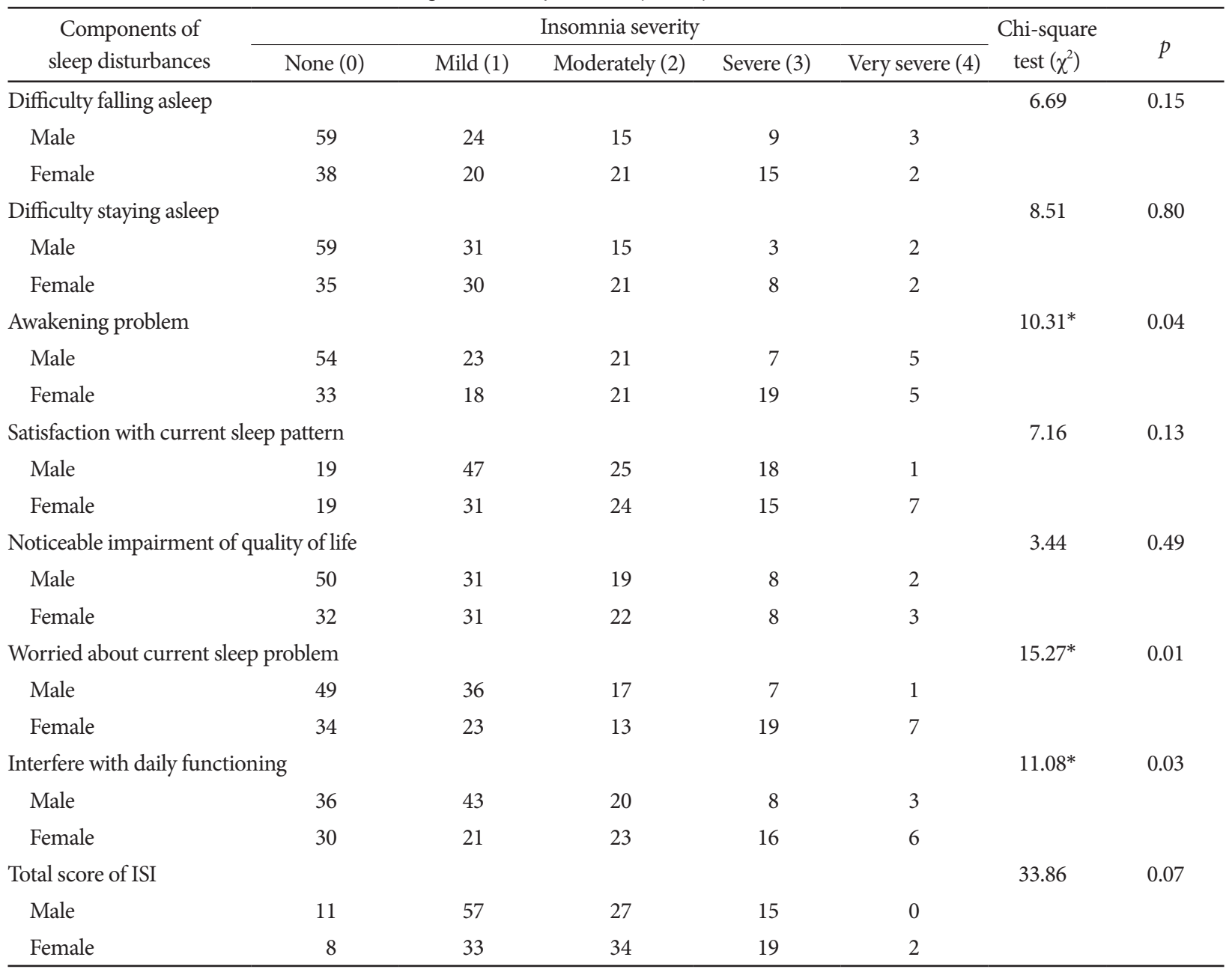

*significant at $p<0.05$. ISI, Insomnia Severity Index; COVID-19, coronavirus disease

disturbances, including insomnia, during than before the COVID-19 pandemic. The sleeping pattern of the general population was affected, and significant differences were found before versus during the pandemic. These findings are consistent with those of a previous study in which $30 \%-40 \%$ of respondents from Hong Kong felt their sleep had worsened and there was a

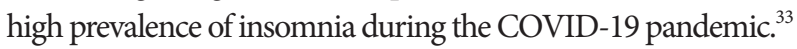

Insomnia is highly prevalent and associated with COVID-19 pandemic-related psychological reactions and poor sleep hygiene. ${ }^{34}$ Our study showed that the prevalence of insomnia was $36.9 \%$ before the COVID-19 pandemic versus $47.1 \%$ during the pandemic, a pattern consistent with that of a study in Italy that reported an increase from $40.5 \%$ to $52.4 \% .^{7}$ A study from China that aimed to assess changes in sleep and psychological reactions during the COVID-19 pandemic reported that the prevalence of insomnia increased significantly i.e. $26.2 \%$ to $33.7 \% .^{34}$ Another study conducted in the Netherlands contradicted this finding, suggesting that sleep quality during the COVID-19 pandemic is correlated with pre-pandemic sleep quality. One-quarter of those participants reported improved sleep quality, although $20 \%$ of good pre-pandemic sleepers reported worse sleep during the lockdown measures. ${ }^{35}$ The study also reported that $11.7 \%$ of the general population had difficulty falling asleep, 5.3\% had difficulty staying asleep, and 12.6\% awakened too early.

Around $11.7 \%$ of our Nepalese participants reported that poor sleep quality interfered with their daily living functions during the lockdown period. Previous studies reported that the prevalence of worsened sleep quality, difficulty falling asleep, and early awakening problems were $38.3 \%, 29.8 \%$, and $29.1 \%$, respectively. ${ }^{34}$ This study reported a significant difference in sleep quality before and during the COVID-19 pandemic with regard to difficulty falling asleep, difficulty staying asleep, satisfaction with current sleep, and worry about sleep problems. These findings are inconsistent with those of a previous study conducted in Italy that focused on perceived sleep quality and psychoemotional well-being. The study's results showed that the $24 \%$ prevalence of insomnia before the COVID-19 pandemic sig- 
Table 6. Correlation of age, sex with sleep disturbances during COVID-19 pandemic $(n=206)$

\begin{tabular}{|c|c|c|c|c|}
\hline \multirow{2}{*}{$\begin{array}{l}\text { Components of } \\
\text { insomnia problem }\end{array}$} & \multicolumn{2}{|c|}{ Age } & \multicolumn{2}{|c|}{ Sex (female) } \\
\hline & r-value & $p$ & r-value & $p$ \\
\hline Difficulty falling asleep & -0.04 & 0.58 & $0.15^{*}$ & 0.03 \\
\hline Difficulty staying asleep & -0.05 & 0.47 & $0.19^{\dagger}$ & 0.01 \\
\hline Awakening problem & -0.10 & 0.15 & $0.19^{\dagger}$ & 0.01 \\
\hline $\begin{array}{l}\text { Satisfaction with current sleep } \\
\text { pattern }\end{array}$ & -0.09 & 0.19 & 0.08 & 0.25 \\
\hline $\begin{array}{l}\text { Noticeable impairment of } \\
\text { quality of life }\end{array}$ & -0.09 & 0.18 & 0.11 & 0.11 \\
\hline $\begin{array}{l}\text { Worried about current sleep } \\
\text { problem }\end{array}$ & -0.001 & 0.99 & $0.23^{\dagger}$ & $<0.01$ \\
\hline Interfere with daily functioning & -0.01 & 0.89 & $0.16^{\dagger}$ & $<0.01$ \\
\hline \multicolumn{5}{|l|}{ Total score of ISI } \\
\hline Before COVID-19 pandemic & -0.08 & 0.25 & 0.59 & 0.03 \\
\hline During COVID-19 pandemic & -0.07 & 0.36 & $0.199^{\dagger}$ & $<0.01$ \\
\hline
\end{tabular}

r-value: Karl-pearson's Coefficient correlation. *significant at $p<$ 0.05 ; ${ }^{\dagger}$ significant at $p \leq 0.001$. ISI, Insomnia Severity Index; COVID-19, coronavirus disease

nificantly increased to $40 \%$ during the pandemic; likewise, the $15 \%$ of subjects who reported difficulty falling asleep increased to $42 \%$, the $19.5 \%$ of subjects who reported difficulty staying asleep increased to $33.7 \%$, and the $24.4 \%$ of subjects who reported early morning awakening problems increased to $38.7 \%{ }^{36}$

A survey of COVID lockdown impact of disrupted sleep patterns in India reported that $67 \%$ of respondents who worked from home had altered sleep schedules, $50 \%$ believed that their sleep pattern had become disrupted, and $81 \%$ felt their sleep schedule would improve after the lockdown. Only $25 \%$ of the respondents had a post-midnight bedtime before versus 35\% after the lockdown, while $25 \%$ of the subjects used to get less than 6 hours of sleep before the lockdown versus 36\% after the lockdown. ${ }^{33}$

There was a statistically significant decrease in sleep disturbances before versus during the COVID-19 pandemic among Nepalese residents. The present study demonstrated that $29.6 \%$ of subjects had subthreshold, $16.5 \%$ had moderate, and $1 \%$ had severe clinical insomnia during the COVID-19 pandemic. An earlier study in India reported that the prevalence of insomnia was $60.5 \%$ (31.8\% with subthreshold, $23.2 \%$ with moderate, and $5.5 \%$ with severe) during the COVID-19 outbreak. ${ }^{37} \mathrm{~A}$ similar study in China reported a 37\% increase in the rate of clinical insomnia before versus during the COVID-19 pandemic. $^{38}$

Another study reported that sleep disturbances have a significant positive relationship with female sex and a negative correlation with age. ${ }^{39}$ The age factor was significantly associated with sleep quality during the COVID-19 pandemic as well as satisfaction with sleep patterns and interference with daily func- tioning. A study conducted in Greece revealed that women's insomnia scores were significantly higher than men's scores and younger age was associated with greater sleep difficulties. ${ }^{40} \mathrm{In}$ the present study, female participants reported facing more problems with waking early, falling asleep, and staying asleep than male participants. Women were more distressed about their current sleeping problems. Women seem to be more vulnerable to stress-related disorders, such as post-traumatic stress disorder and anxiety. ${ }^{41}$

The current study showed that the prevalence of insomnia was higher among female participants, while subjects younger than 45 years old more commonly had clinically severe insomnia. A cross-sectional study in China demonstrated that the combination of anxiety and stress reduces the positive effects of social capital on sleep quality. ${ }^{42}$ Another study of the influence of coronavirus disease on sleep quality in China demonstrated that participants with a Wuhan exposure history generally showed longer sleep latency $\left(\chi^{2}=9.77, p<0.05\right)$, which confirmed that subjective sleep quality, delayed sleep onset, sleep fragmentation, and sleep duration all regulated the effect of Wuhan exposure history on post-traumatic stress disorder. The study findings suggested that sleep quality levels decreased and posttraumatic stress symptoms increased with time. ${ }^{43} \mathrm{~A}$ previous study aimed to assess the mental health burden of the Chinese public during the outbreak and stated that $18.2 \%$ of the public had poor sleep quality, while healthcare workers (23.6\%) were more likely to have poor sleep quality and reported the highest rate of poor sleep quality $(p<0.001) .{ }^{44}$ Our study findings also indicated that sleep pattern changes were evident after the country went into complete lockdown.

Thus, our study pointed out the fact that stress in the form of the COVID-19 pandemic and lockdown significantly affects the quality of life of Nepalese citizens. Nepal is an economically lower nation; the lockdown has played a greater role in joblessness and lower income, resulting in various health issues that most prominently manifest as sleep pattern changes. Our findings may provide support for the implementation of measures to improve sleep quality and reduce the impact of the COVID-19 pandemic on sleep quality among Nepalese residents. We recognize some limitations of this study, including its small size of 206 participants and the self-reported questionnaire, the use of which was necessary due to the lack of direct contact with people during the lockdown. Further studies should assess other factors contributing to insomnia.

In conclusion, our study revealed a high prevalence of poor sleep among Nepalese residents. The ISI is an eye-opener for the mostly ignored fact of sleep patterns. It showed that sleep disturbances significantly increased before versus during the COVID-19 pandemic among Nepalese residents. Public awareness should be increased through proper health education about 
the importance of good sleep quality for maintaining one's mental health and reducing the prevalence of insomnia during the COVID-19 pandemic and lockdown.

\section{Conflicts of Interest}

The authors have no potential conflicts of interest to disclose.

\section{ORCID iDs}

Avinash Chandra https://orcid.org/0000-0002-3895-5369

Ayush Chandra https://orcid.org/0000-0002-8813-2838

\section{Author Contributions}

Conceptualization: Avinash Chandra. Data Curation: Avinash Chandra. Formal analysis: Ayush Chandra. Investigation: Ayush Chandra. Methodology: Nabina Sharma. Project administration: Ayush Chandra. Resources: Avinash Chandra. Software: Nabina Sharma. Supervision: Avinash Chandra. Validation: Ayush Chandra. Visualization: Ayush Chandra. Writingoriginal draft: Pooja Prakash. Writing—review \& editing: Ayush Chandra, Avinash Chandra.

\section{Funding Statement}

None.

\section{Acknowledgments}

We acknowledge the cooperation and support of all participants for the time and effort they devoted to the study.

\section{REFERENCES}

1. Purves D, Augustine GJ, Fitzpatrick D, et al. Why do humans and many other animals sleep? Neuroscience 2nd ed. [Internet]. Sunderland: Sinauer Associates, 2001. Available from: https://www.ncbi.nlm. nih.gov/books/NBK11108/.

2. Tononi G, Cirelli C. Sleep and the price of plasticity: from synaptic and cellular homeostasis to memory consolidation and integration. Neuron 2014;81:12-34. https://doi.org/10.1016/j.neuron.2013.12.025.

3. Edwards RR, Almeida DM, Klick B, Haythornthwaite JA, Smith MT. Duration of sleep contributes to next-day pain report in the general population. Pain 2008;137:202-207. https://doi.org/10.1016/j.pain.2008.01.025.

4. Gómez-González B, Domínguez-Salazar E, Hurtado-Alvarado G, et al. Role of sleep in the regulation of the immune system and the pituitary hormones. Ann N Y Acad Sci 2012;1261:97-106. https://doi.org/10.1111/ j.1749-6632.2012.06616.x.

5. American Psychiatric Association. What are sleep disorders? [Internet]. Washington, DC: American Psychiatric Association [cited 2021 Apr 1]. Available from: https://www.psychiatry.org/patients-families/ sleep-disorders/what-are-sleep-disorders.

6. Groeger JA, Zijlstra FR, Dijk DJ. Sleep quantity, sleep difficulties and their perceived consequences in a representative sample of some 2000 British adults. J Sleep Res 2004;13:359-371. https://doi.org/10.1111/ j.1365-2869.2004.00418.x.

7. Cellini N, Canale N, Mioni G, Costa S. Changes in sleep pattern, sense of time and digital media use during COVID-19 lockdown in Italy. J Sleep Res 2020;29:e13074. https://doi.org/10.1111/jsr.13074.

8. Al Maqbali M, Al Sinani M, Al-Lenjawi B. Prevalence of stress, depression, anxiety and sleep disturbance among nurses during the COVID-19 pandemic: a systematic review and meta-analysis. J Psychosom Res 2021;141:110343. https://doi.org/10.1016/j.jpsychores.2020.110343.

9. Reddy EV, Kadhiravan T, Mishra HK, et al. Prevalence and risk factors of obstructive sleep apnea among middle-aged urban Indians: a community-based study. Sleep Med 2009:10:913-918. https://doi.org/10.1016/j. sleep.2008.08.011.
10. Zhang R, Wang X, Ni L, et al. COVID-19: melatonin as a potential adjuvant treatment. Life Sci 2020;250:117583. https://doi.org/10.1016/j. lfs.2020.117583.

11. Wu KK, Chan SK, Ma TM. Posttraumatic stress, anxiety, and depression in survivors of severe acute respiratory syndrome (SARS). J Trauma Stress 2005;18:39-42. https://doi.org/10.1002/jts.20004.

12. Rogers JP, Chesney E, Oliver D, et al. Psychiatric and neuropsychiatric presentations associated with severe coronavirus infections: a systematic review and meta-analysis with comparison to the COVID-19 pandemic. Lancet Psychiatry 2020;7:611-627. https://doi.org/10.1016/S22150366(20)30203-0.

13. Moldofsky H, Patcai J. Chronic widespread musculoskeletal pain, fatigue, depression and disordered sleep in chronic post-SARS syndrome; a casecontrolled study. BMC Neurol 2011;11:37. https://doi.org/10.1186/14712377-11-37.

14. Acharibasam JW, Chireh B, Menegesha HG. Assessing anxiety, depression and insomnia symptoms among Ebola survivors in Africa: a meta-analysis. PLoS One 2021;16:e246515. https://doi.org/10.1371/journal.pone.0246515.

15. Jahrami H, BaHammam AS, Bragazzi NL, Saif Z, Faris M, Vitiello MV. Sleep problems during the COVID-19 pandemic by population: a systematic review and meta-analysis. J Clin Sleep Med 2021;17:299-313. https://doi.org/10.5664/jcsm.8930.

16. World Health Organization. Country \& technical guidance - Coronavirus disease (COVID-19) [Internet]. Geneva: World Health Organization [cited 2021 Apr 1]. URL: https://www.who.int/emergencies/diseases/novel-coronavirus-2019/technical-guidance.

17. World Health Organization. Coronavirus disease (COVID-2019) situation report-113 [Internet]. Geneva: World Health Organization [cited 2021 Apr 1]. Available from: https://www.who.int/emergencies/diseases/novel-coronavirus-2019/situation-reports.

18. Nepalese Ministry of Health and Population, Department of Health Services, Epidemiology and Disease Control Division. Links for COVID-19 news \& information [Internet News]. Kathmandu: Epidemiology and Disease Control Division, 2020 Mar 8 [cited 2021 Apr 1]. Available from: http://www.edcd.gov.np/news/links-for-covid19-news-and-information.

19. University of Strathclyde. Advice on protecting sleep during COVID-19 pandemic [Internet News]. Glasgow: University of Strathclyde, 2020 Apr 8 [cited 2021 Apr 1]. Available from: https://www.strath. ac.uk/whystrathclyde/news/adviceonprotectingsleepduringcovid19pandemic/.

20. Chengappa S. Covid impact: lockdownhas disrupted sleep patterns among Indians, say survey by Wakefit.co [Internet News]. Chennai: The Hindu BusinessLine, 2020 Apr 12 [cited 2021 Apr 1]. Available from: https://www.thehindubusinessline.com/news/variety/covid-impact-lockdown-has-disrupted-sleep-patterns-among-indians-sayssurvey-by-wakefitco/article31321598.ece\#.

21. Ara T, Rahman MM, Hossain MA, Ahmed A. Identifying the associated risk factors of sleep disturbance during the COVID-19 lockdown in Bangladesh: a web-based survey. Front Psychiatry 2020;11:580268. https://doi.org/10.3389/fpsyt.2020.580268.

22. Yadav R, Yadav P, Kumar SS, Kumar R. Assessment of depression, anxiety, and sleep disturbance in COVID-19 patients at tertiary care center of North India. J Neurosci Rural Pract 2021;12:316-322. https:// doi.org/10.1055/s-0040-1722811.

23. Khanal P, Devkota N, Dahal M, Paudel K, Joshi D. Mental health impacts among health workers during COVID-19 in a low resource setting: a cross-sectional survey from Nepal. Global Health 2020;16:89. https://doi.org/10.1186/s12992-020-00621-z.

24. Deng J, Zhou F, Hou W, et al. The prevalence of depression, anxiety, and sleep disturbances in COVID-19 patients: a meta-analysis. Ann $N$ Y Acad Sci 2021;1486:90-111. https://doi.org/10.1111/nyas.14506.

25. Wang S, Zhang Y, Ding W, et al. Psychological distress and sleep problems when people are under interpersonal isolation during an epi- 
demic: a nationwide multicenter cross-sectional study. Eur Psychiatry 2020;63:e77. https://doi.org/10.1192/j.eurpsy.2020.78.

26. Grima NA, Bei B, Mansfield D. Insomnia theory and assessment. Aust J Gen Pract 2019;48:193-197. https://doi.org/10.31128/AJGP-12-184780.

27. Santin LM, Granizo AEC, Cordova J. Factors associated with insomnia in the Peruvian population during social isolation due to the COVID-19 pandemic. Neurology 2021;96(15 Suppl):4968. Available from: https://n.neurology.org/content/96/15_Supplement/4968.

28. Kaltwasser J. Study: COVID-19 health care workers face higher risk of insomnia [Internet News]. Cranbury: Contagion Live, 2020 Apr 17 [cited 2021 Apr 1]. Available from: https://www.contagionlive.com/news/ study-covid19-health-care-workers-face-higher-risk-of-insomnia.

29. Israel GD. Determining sample size [Internet]. Gainesville: University of Florida, Institute of Food and Agricultural Sciences, 2012 [cited 2021 Apr 1]. Available from: https://www.psycholosphere.com/Determining\%20sample\%20size\%20by\%20Glen\%20Israel.pdf.

30. American Psychiatric Association. Diagnostic and statistical manual of mental disorders: DSM-IV. 4th ed. Washington, DC: American Psychiatric Association, 1994.

31. Bastien $\mathrm{CH}$, Vallières A, Morin CM. Validation of the insomnia severity index as an outcome measure for insomnia research. Sleep Med 2001; 2:297-307. https://doi.org/10.1016/s1389-9457(00)00065-4.

32. Salata C, Calistri A, Parolin C, Palù G. Coronaviruses: a paradigm of new emerging zoonotic diseases. Pathog Dis 2019;77:ftaa006. https:// doi.org/10.1093/femspd/ftaa006.

33. Yu BY, Yeung WF, Lam JC, et al. Prevalence of sleep disturbances during COVID-19 outbreak in an urban Chinese population: a crosssectional study. Sleep Med 2020;74:18-24. https://doi.org/10.1016/ j.sleep.2020.07.009.

34. Li Y, Qin Q, Sun Q, Sanford LD, Vgontzas AN, Tang X. Insomnia and psychological reactions during the COVID-19 outbreak in China. $J$ Clin Sleep Med 2020;16:1417-1418. https://doi.org/10.5664/jcsm.8524.

35. Kocevska D, Blanken TF, Van Someren EJW, Rösler L. Sleep quality during the COVID-19 pandemic: not one size fits all. Sleep Med 2020; 76:86-88. https://doi.org/10.1016/j.sleep.2020.09.029.

36. Marelli S, Castelnuovo A, Somma A, et al. Impact of COVID-19 lockdown on sleep quality in university students and administration staff. $J$ Neurol 2021;268:8-15. https://doi.org/10.1007/s00415-020-10056-6.

37. Jain A, Singariya G, Kamal M, Kumar M, Jain A, Solanki RK. COVID-19 pandemic: psychological impact on anaesthesiologists. Indian J Anaesth 2020;64:774-783. https://doi.org/10.4103/ija.IJA_697_20.

38. Lin LY, Wang J, Ou-yang X, et al. The immediate impact of the 2019 novel coronavirus (COVID-19) outbreak on subjective sleep status. Sleep Med 2020;77:348-354. https://doi.org/10.1016/j.sleep.2020.05.018

39. Keshavarz Akhlaghi AA, Ghalehbandi MF. Sleep quality and its correlation with general health in pre-university students of Karaj, Iran. Iran J Psychiatry Behav Sci 2009;3:44-49.

40. Voitsidis P, Gliatas I, Bairachtari V, et al. Insomnia during the COVID-19 pandemic in a Greek population. Psychiatry Res 2020;289:113076. https://doi.org/10.1016/j.psychres.2020.113076.

41. Li SH, Graham BM. Why are women so vulnerable to anxiety, traumarelated and stress-related disorders? The potential role of sex hormones. Lancet Psychiatry 2017;4:73-82. https://doi.org/10.1016/S22150366(16)30358-3.

42. Xiao H, Zhang Y, Kong D, Li S, Yang N. Social capital and sleep quality in individuals who self-isolated for 14 days during the coronavirus disease 2019 (COVID-19) outbreak in January 2020 in China. Med Sci Monit 2020;26:e923921. https://doi.org/10.12659/MSM.923921.

43. Zhang F, Shang Z, Ma H, et al. High risk of infection caused posttraumatic stress symptoms in individuals with poor sleep quality: a study on influence of coronavirus disease (COVID-19) in China [Preprint]. medRxiv 2020 Mar 24 [cited 2021 Apr 1]. Available from: https://doi. org/10.1101/2020.03.22.20034504.

44. Huang Y, Zhao N. Generalized anxiety disorder, depressive symptoms and sleep quality during COVID-19 outbreak in China: a web-based cross-sectional survey. Psychiatry Res 2020;288:112954. https://doi. org/10.1016/j.psychres.2020.112954. 